\title{
Transfección de la línea celular de salmón CHSE-214 usando un liposoma no comercial ${ }^{\#}$
}

\author{
Transfection of salmon cellular line CHSE-214 using a non-commercial liposome \\ M Aranda ${ }^{1 *}$, M Reyes 2 , C Ramírez ${ }^{2}$ \\ ${ }^{1}$ Departamento de Bromatología, Facultad de Farmacia, Universidad de Concepción. \\ ${ }^{2}$ Facultad de Ingeniería y Biotecnología, Universidad San Sebastián.
}

\begin{abstract}
SUMMARY
The fast growth of Chilean aquaculture has impelled the exploration of new strategies of sanitary prevention. DNA vaccines appear as a feasible alternative for disease control, however there are technical barriers such as the form of administration and the carrier systems which need to be resolved. Liposomes are widely used for gene delivery in mammalian cell lines, but their high cost makes difficult their use at an industrial scale. Considering this economic problem and in order to contribute with an in vitro procedure for transfection of salmon cells, the objectives of this work were to formulate a liposome from DOTAP lyophilized powder and to develop a transfection protocol using eukaryotic vectors for the fish cell line CHSE-214. The liposome properties and the optimal transfection conditions were established using pcDNA 4.0 HisMax I TOPO and pIRES-EGFP vectors and Chinook CHSE-214 cell line (ATCC 1681). The results indicated that the liposome formulated from DOTAP lyophilized powder shares all the characteristics with the commercial liposomes and has a lower cost, approximately 10 times less. By using this liposome, it was possible to develop a transfection protocol for CHSE-214 fish cells with eukaryotic vectors without toxicity signs which allowed the expression, in both vectors, of the incorporated gene.
\end{abstract}

Palabras clave: liposoma, DOTAP, transfección, CHSE-214, salmón.

Key words: liposome, DOTAP, transfection, CHSE-214, salmon.

\section{INTRODUCCION}

La industria acuícola chilena se ha convertido en los últimos años en una de las más importantes del mundo, donde sólo en el período enero-septiembre del 2005 alcanzó los US\$ 1.150 millones en exportaciones, cifra superior en un $13 \%$ a igual período del 2004. Esta alza se ve afectada, ya que las condiciones de este tipo de cultivo (sobrepoblación) facilitan la transmisión de diferentes enfermedades, dificultando su control y convirtiendo a este ítem en la principal pérdida de biomasa. Anualmente cerca de US\$ 100 millones son perdidos debido a enfermedades que afectan en distintas etapas la producción de salmonideos ${ }^{1}$, dentro de las cuales destacan el síndrome del alevín de la trucha arco iris (RTFS), el virus de la necrosis pancreática infecciosa (IPNV), la furunculosis y la enfermedad rickettsial del salmón. Para tratar o prevenir dichas enfermedades se utiliza, dependiendo del patógeno, la administración de antibióticos y/o vacunas. Desafortunadamente la aplicación de estas últimas encarece

Aceptado: 10.10.2006

* Barrio Universitario s/n, casilla 237, Concepción, Chile. Teléfono: +56 41 2204544. Fax: +56 41 2210568. E-mail: maranda@udec.cl

\# Financiado por INNOVA Bío-Bío y la Universidad de Concepción.

1 Informe Económico Salmonicultura 2005. Asociación de la Industria del Salmón de Chile A.G. enormemente los costos porque deben ser aplicadas pez a pez y muchas veces no es posible su uso en etapas tempranas de cultivo de alevines por su pequeño tamaño. Dentro de este contexto, las vacunas entregadas masivamente, ya sea vía oral o por inmersión, constituyen una solución viable a esta problemática. El mercado chileno cuenta actualmente con una vacuna de administración oral contra IPNV reconocida por la autoridad de salud pecuaria nacional, Aquavac IPN oral de Schering Plough; no obstante lo anterior, aún existen barreras clínicas, tecnológicas y económicas que subsanar para mejorar su aceptación dentro de la empresa salmonicultora.

Dentro de las vacunas que se pueden entregar vía oral o por inmersión se encuentran las vacunas de ADN. El punto crítico para esta alternativa es la eficacia de la transferencia del ADN foráneo y su posterior expresión en las células blanco (Ahearn y Malone 1999), para lo cual es necesario contar con un vehículo que proteja al ADN y que además sea absorbido por las células blanco para incorporar este material genético. Dentro de estos vehículos los vectores virales como el adenovirus recombinante son una alternativa eficiente para la entrega de genes en líneas celulares; sin embargo, su utilidad se ve notablemente reducida por los riesgos inherentes en su uso, como respuestas inmunes severas y reversión (Felgner y col 1994). Dado esto último, se han realizado numerosos esfuerzos por desarrollar vectores no virales o sintéticos, 
con baja toxicidad y sin actividad inmune. Los liposomas catiónicos pertenecen a esta nueva clase de vehículos (Felgner y col 1994, Rädler y col 1997, Moret y col 2001), y ya se han convertido en una herramienta fundamental para transferir el ADN in vitro. Aunque su eficacia es mil veces menor que los vectores virales (Moret y col 2001), la seguridad en su uso los hace preferibles (Ahearn y Malone 1999, Marshall y col 1999, Simberg y col 2001). La interacción basada en la atracción por cargas entre el liposoma y el ADN permite la formación de un complejo, generalmente conocido como lipoplex (Wiethoff y col 2002), que es fundamental para una entrega eficiente del ADN a la célula blanco vía endocitosis (Felgner y col 1987, Felgner y col 1994, Zabner y col 1995, Xu y Szoka 1996). Dentro de los liposomas catiónicos, DOTAP (1,2dioleoil-3-trimetilamonio-propano) es uno de los más usados para la entrega de genes in vitro en líneas celulares mamíferas y varios grupos han estudiado sus características (Zabner y col 1995, Xu y col 1999, Yu y Lin 2000, Wiethoff y col 2002), desafortunadamente su alto costo hace prohibitivo su uso en escala comercial. Estudios recientes han reportado que la inmunización de peces vía inmersión usando formulaciones con liposomas catiónicos produjo efectos tóxicos, asociados a la interacción entre el mucus de las agallas y el liposoma catiónico la cual reduce el intercambio del oxígeno produciendo la hipoxia de los peces (Romoren y col 2002, Romoren y col 2004 a). Por lo tanto, la inmunización de peces vía oral representa un gran desafío, donde la protección que confiere el liposoma podría desempeñar un papel preponderante en la entrega de las vacunas de ADN a través de los alimentos para peces. Con el fin de abordar la problemática económica en la obtención del liposoma y para contribuir con un procedimiento de transfección in vitro en células de salmón, los objetivos de este trabajo fueron formular un liposoma a partir de polvo liofilizado de DOTAP y desarrollar un protocolo de transfección de vectores eucarióticos en la línea celular de salmón CHSE-214 proveniente del riñón embrionario de salmón Oncorhynchus tchawitsha.

\section{MATERIAL Y METODOS}

Vectores y cultivos celulares. Los vectores pcDNA 4.0 HisMax I TOPO (Invitrogen, Carlsbad, CA, EE.UU.) y pIRES-EGFP (Clontech, CA, EE.UU.) fueron ligados con una secuencia quimérica obtenida por la acción de transcriptasa reversa y reacción en cadena de la polimerasa (RT-PCR) usando como templado el segmento A de IPNV, virus perteneciente al género aquabirnavirus (Weber y col 2001). Los cebadores empleados fueron específicos para amplificar la zona media de la secuencia de la proteína viral 2 (VP2). La amplificación del plásmido (ADNp) fue realizada en cultivos de $E$. coli JM109 (Promega, Madison, WI, EE.UU.) y su purificación usando el Quantum Miniprep (BioRad, Hercules,
CA, EE.UU.). Las células embrionarias de salmón Chinook CHSE-214 (ATCC 1681) fueron cultivadas en monocapas al $80 \%$ de confluencia en un medio esencial mínimo (MEM) con bicarbonato de sodio $(2,2 \mathrm{~g} / \mathrm{L}$, Merck, Darmstadt, Alemania) y suero fetal bovino (FBS, Gibco, Carlsbad, CA, EE.UU.) entre $2-5 \%$ a $20{ }^{\circ} \mathrm{C}$. Cada 10 días las células fueron subcultivadas usando $1 \mathrm{~mL}$ de tripsina con una concentración de $2,5 \mathrm{mg} / \mathrm{mL}$ (Sigma, St. Louis, MO, EE.UU.) y $1 \mathrm{mM}$ de EDTA (Merck) durante 10 minutos a temperatura ambiente.

Preparación del liposoma. $10 \mathrm{mg}$ de cloruro de DOTAP (Sigma) fueron disueltos con $5 \mathrm{~mL}$ de cloroformo en un matraz Erlenmeyer de $50 \mathrm{~mL}$; el cloroformo fue evaporado bajo corriente de nitrógeno para formar una película lipídica, que fue expuesta a alto vacío por 2 horas. La suspensión de liposomas formada fue diluida con $10 \mathrm{~mL}$ de agua estéril para obtener una concentración aproximada de $1 \mathrm{mg} / \mathrm{mL}$ (Jork y col 1990). La suspensión fue colocada en un baño de ultrasonido por 30 minutos, para luego filtrarla a un tubo estéril dentro de una cámara de flujo laminar usando un filtro-jeringa de $0,22 \mu \mathrm{m}$ y almacenada finalmente a $4{ }^{\circ} \mathrm{C}$.

Microscopía electrónica. La morfología de los liposomas preparados con este procedimiento fue examinada usando microscopía electrónica de transmisión (TEM) con un microscopio EX II de Jeol/de Jem 1200 (Tokio, Japón). La preparación de la muestra fue realizada de acuerdo al protocolo del fabricante y a Moret y col (2001).

Condiciones de transfección. Las condiciones óptimas de transfección fueron definidas usando combinaciones en masa ADNp: DOTAP entre 1:1 a 1:9,2 $\mu \mathrm{g} / \mu \mathrm{g}$ de acuerdo a un diseño experimental central compuesto (cuadro 1). El vector empleado correspondió a pcDNA 4.0 HisMax I TOPO más inserto dado el alto nivel de expresión reportado por el fabricante Invitrogen. Las cantidades requeridas de ADNp y de DOTAP fueron adicionadas a 2 alícuotas de $100 \mu \mathrm{l}$ de MEM, para luego ser mezcladas e incubadas por 30 minutos. Células CHSE214 fueron cultivadas a $80 \%$ de confluencia en placas de 12 pocillos, conteniendo aproximadamente $1,5 \times 10^{3}$ células $/ \mathrm{mm}^{2}$. Las monocapas subconfluentes fueron lavadas 2 veces con tampón fosfato salino (PBS), después de lo cual la mezcla preparada de lipoplex fue agregada a un volumen final de $0,5 \mathrm{~mL}$ de MEM por pocillo. Una vez transcurrido el tiempo de transfección ( 0,5 a 3,5 horas) a $20{ }^{\circ} \mathrm{C}$ las monocapas fueron lavadas nuevamente con 2 porciones de PBS, con la finalidad de remover el lipoplex no incorporado a las células y se agregó medio MEM más suero fetal bovino $2 \%$. El tiempo de incubación considerado estuvo en un rango de 3,5 a 44,0 horas a $20{ }^{\circ} \mathrm{C}$, luego de lo cual las células fueron lisadas con Trizol (Invitrogen). Células con o sin transfectar fueron evaluadas morfológicamente mediante microscopía 
Cuadro 1. Diseño experimental para determinar las condiciones óptimas de transfección para la línea celular CHSE-214. Experimental design to determine the optimal transfection conditions for CHSE-214 cell line.

\begin{tabular}{|c|c|c|c|c|}
\hline $\begin{array}{c}\text { Relación } \\
\text { DOTAP/ADN }\end{array}$ & $\begin{array}{c}\text { Plásmido } \\
\mu \mathrm{g}\end{array}$ & $\begin{array}{c}\text { DOTAP } \\
\mu \mathrm{g}\end{array}$ & $\begin{array}{l}\text { Transfección } \\
\text { (horas) }\end{array}$ & $\begin{array}{c}\text { Incubación } \\
\text { (horas) }\end{array}$ \\
\hline \multicolumn{5}{|l|}{ Placa A-1 } \\
\hline 4,0 & 1,2 & 4,80 & 1,0 & 12,0 \\
\hline 6,0 & 1,2 & 7,20 & 0,5 & 24,0 \\
\hline 4,0 & 1,2 & 4,80 & 1,0 & 36,0 \\
\hline 2,6 & 1,2 & 3,12 & 2,0 & 24,0 \\
\hline 6,0 & 1,2 & 7,20 & 2,0 & 44,0 \\
\hline 8,0 & 1,2 & 9,60 & 3,0 & 36,0 \\
\hline 8,0 & 1,2 & 9,60 & 1,0 & 12,0 \\
\hline 6,0 & 1,2 & 7,20 & 2,0 & 24,0 \\
\hline 10 & 1,2 & 1,20 & 2,0 & 24,0 \\
\hline Plásmido & 1,2 & - & 2,0 & 24,0 \\
\hline DOTAP & - & 7,20 & 2,0 & 24,0 \\
\hline Células & - & - & 2,0 & 24,0 \\
\hline \multicolumn{5}{|l|}{ Placa A-2 } \\
\hline 6,0 & 1,2 & 7,20 & 2,0 & 24,0 \\
\hline 8,0 & 1,2 & 9,60 & 3,0 & 12,0 \\
\hline 8,0 & 1,2 & 9,60 & 1,0 & 36,0 \\
\hline 6,0 & 1,2 & 7,20 & 2,0 & 3,50 \\
\hline 4,0 & 1,2 & 4,80 & 3,0 & 12,0 \\
\hline 6,0 & 1,2 & 7,20 & 3,5 & 24,0 \\
\hline 4,0 & 1,2 & 4,80 & 3,0 & 36,0 \\
\hline 9,2 & 1,2 & 11,00 & 2,0 & 24,0 \\
\hline 1,0 & 1,2 & 1,20 & 2,0 & 24,0 \\
\hline Plásmido & 1,2 & - & 2,0 & 36,0 \\
\hline DOTAP & - & 7,20 & 2,0 & 36,0 \\
\hline Células & - & - & 2,0 & 36,0 \\
\hline
\end{tabular}

de contraste de fase con un aumento de 40 veces (Olympus BX51) para determinar si se aprecia efecto citopático del cultivo en monocapa. El uso del vector pIRES-EGFP con inserto de IPNV se limitó a probar, en forma sencilla, si existía transfección en la línea celular de pez a distintos tiempos de incubación.

Extracción y cuantificación del ADN. La extracción del plásmido y del ácido ribonucleico total (ARN) fue realizada con Trizol (Invitrogen) de acuerdo con el protocolo descrito por el fabricante. Los ensayos de expresión del plásmido en la línea celular se realizaron usando RT-PCR a partir de ARNm extraído según la técnica publicada por Weber y col (2001). ${ }^{2}$ Controles de contaminación por plásmido y restos de ADN cromosomal fueron realizados para cada reacción ejecutada. El plásmido y los amplicones fueron cargados sobre un gel de agarosa al $1 \%$, separados por electroforesis y visualizados con bromuro de etidio $0,5 \mu \mathrm{g} / \mathrm{mL}$ (Winkler, Santiago, Chile).

2 Los partidores utilizados en el presente estudio se encuentran en una carpeta en trámite para obtener su patente.
Las imágenes obtenidas con el sistema de fotodocumentación UVP 4.5.1 fueron analizadas usando los programas Doc-it 2.0 e Image Pro plus.

Protección del liposoma y su estabilidad. Para evaluar la estabilidad del lipoplex durante la transfección, dos variables fueron seleccionadas, la presencia de nucleasas y de polianiones. $300 \mathrm{ng}$ del plásmido libre o incorporado en el lipoplex fueron incubados por $0,10,20$ y 30 minutos con 10 unidades (U) de ADNsa I (Invitrogen) a $37{ }^{\circ} \mathrm{C}$. La inestabilidad del complejo ADNp/DOTAP en presencia del polianión fue estudiada usando heparina al $2 \%$ y $5 \%$ por 10 minutos seguidos por la adición de $10 \mathrm{U}$ de ADNsa I. Las reacciones de digestión fueron detenidas con EDTA 0,5 M. El efecto se evaluó al observar los perfiles de migración del plásmido a través de la visualización de geles de agarosa al $1 \%$ teñidos con bromuro de etidio $(0,5 \mu \mathrm{g} / \mathrm{mL})$.

Análisis estadístico. Los diseños experimentales y el análisis estadístico fueron realizados con el programa Statgraphics 3.00.11. 


\section{RESULTADOS Y DISCUSION}

En este trabajo se logró la transfección de la línea celular de peces CHSE-214 usando un liposoma no comercial de DOTAP; esto es relevante, considerando que mayoritariamente se han utilizado líneas celulares mamíferas para realizar este tipo de ensayos (Romoren y col $2004^{\text {b }}$ ). Los resultados de este trabajo también indican que el liposoma no comercial presentó la misma forma, tamaño y confirió un nivel de protección similar al liposoma comercial (según referencias del fabricante Biontex $2003^{3}$ ). De la evaluación del costo de fabricación a nivel de laboratorio, considerando el proceso de manufactura completo, se estimó una diferencia de 10 veces con respecto al precio de venta de la alternativa anteriormente planteada. Esto en principio favorecería su uso en escala productiva. Efecto citopático visible descrito a altas concentraciones de DOTAP (> $100 \mu \mathrm{g} /$ $\mathrm{mL}$ ) (Romoren y col 2004 ${ }^{\mathrm{b}}$ ) no fue observado a las concentraciones usadas en este trabajo $(<22 \mu \mathrm{g} / \mathrm{mL})$ en células CHSE-214 transfectadas.

Tamaño y forma del liposoma no comercial de DOTAP. Bajo microscopía electrónica de transmisión se observó que el liposoma no comercial de DOTAP adoptó una forma homogénea, con un tamaño cercano a $200 \mathrm{~nm}$ (figura 1), concordando con lo descrito por otros autores (Zabner y col 1995, Xu y col 1999, Simberg y col 2001).

Condiciones óptimas de transfección. El efecto de las variables relación ADNp/DOTAP, tiempo de transfección e incubación fue evaluado en referencia a la cantidad de plásmido recuperado (figura 2). Después del análisis estadístico se determinó que las condiciones óptimas de transfección fueron una relación ADNp:DOTAP 1:4, tiempo de transfección 3 horas y tiempo de incubación 12 horas. Las experiencias desarrolladas consideraron réplicas para estimar el error y definir mediante ANOVA los efectos significativos. Todas las variables en estudio obtuvieron valor-p menores a 0,05 . Considerando el resultado anterior y el número de células sometidas a la transfección se estimó teóricamente que la cantidad de liposoma no comercial (12 pg/célula) utilizada para los estudios de transfección fue aproximadamente dos veces menor que la descrita en la literatura de productos comerciales (26 pg/célula) para una experiencia equivalente (Roche $1999^{4}$, Biontex $2003^{3}$ ).

3 Biontex. 2003. Dotap Liposomal Transfection. http: //www. biontex.de/

4 Roche. 1999. Dotap Liposomal Transfection Reagent (online). Mannheim, Germany, Roche Diagnostics GmbH. http: // www.roche-applied-science.com/pack-insert/1811177a.pdf

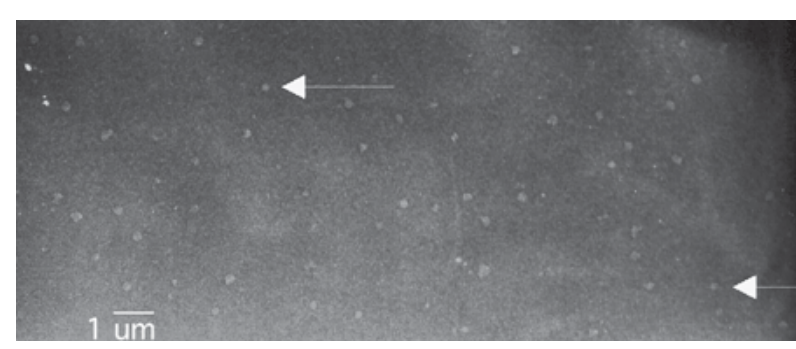

Figura 1. Morfología de los liposomas. Microscopía electrónica de transmisión fue empleada para observar tamaño y forma de los liposomas formulados a partir de DOTAP liofilizado. La microfotografía muestra una distribución uniforme de tamaños inferiores a $200 \mathrm{~nm}$.

Liposomes morphology. Transmission electronic microscopy was used to observe size and shape of liposome made from DOTAP powder. Uniform distribution was achieved at lower than $200 \mathrm{~nm}$ diameter.

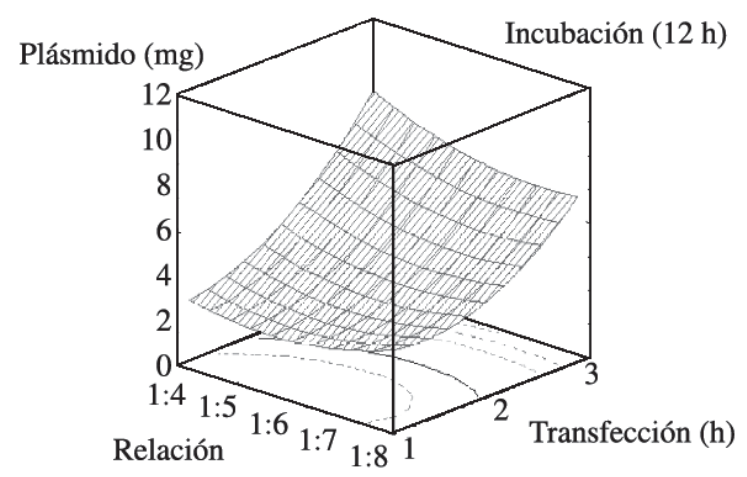

Figura 2. Condiciones óptimas de transfección de células $\boldsymbol{C H S E - 2 1 4 . ~ E l ~ e f e c t o ~ d e ~ l a ~ r e l a c i o ́ n ~ e n ~ m a s a ~ d e ~ A D N p / D O T A P , ~}$ tiempo de transfección y tiempo de incubación fue evaluado bajo un diseño experimental. El plásmido incorporado y sintetizado in vitro fue aislado por Trizol y cuantificado mediante densitometría de geles de agarosa teñidos con bromuro de etidio cargados con muestras de lisado celular.

Study of the optimal transfection of CHSE-2143 cells conditions. The mass relation effect of DNAp/DOTAP, as well as the transfection and incubation times were evaluated using an experimental design. The uptaken and in vitro synthesized plasmid was isolated with Trizol and quantified by densitometry using agarose gel dyed with bromide ethidium.

Protección frente a ADNsa I. Usando la razón óptima entre ADNp y DOTAP (1:4), se evaluó el nivel de protección del lipoplex frente a la digestión de la ADNsa I. El plásmido desnudo (300 ng) fue digerido totalmente por la acción de la nucleasa; contrariamente, una mínima fracción del ADNp en el lipoplex fue degradada. El nivel de protección del liposoma indica que este vehículo cubre el ADNp lo suficiente y su interacción no es afectada por la temperatura $\left(37^{\circ} \mathrm{C}\right)$ o por la adición de electrólitos necesarios para obtener una actividad adecuada de la ADNsa (figura 3). 
Interacción plásmido-liposoma. Diferentes autores (Xu y Szoka 1996; Zelphati y Szoka 1996; Perrie y col 2001) han reportado que solamente las moléculas con un exceso de cargas negativas como la heparina y los dextranos causan una liberación substancial (> 60\%) del plásmido cubierto por liposoma. Esto fue confirmado cuando el plásmido contenido en el lipoplex fue degradado totalmente bajo combinación de las actividades de la heparina (2\%) y de la ADNsa I. Este resultado demostró que la relación entre el liposoma y el ADNp está basada en sus cargas y que hay un desplazamiento del plásmido por parte del polianión (figura 4).

Expresión del gen reportero en las células transfectadas. La expresión in vitro fue determinada por RT-PCR del ARNm sintetizado a partir del fragmento quimérico clonado en ambos vectores eucarióticos (figura 5). Las extracciones de ARN total se realizaron a las 6, 12 y 24 horas de incubación posteriores a 3 horas de transfección. Además, la expresión del gen fue visualizada usando microscopía de fluorescencia para detectar la proteína fluorescente verde, incorporada en el vector pIRES (datos no incluidos).
Los resultados permiten concluir que el liposoma formulado desde polvo liofilizado de DOTAP presenta un comportamiento similar en términos de transfección y estabilidad que los liposomas comerciales usados como referencias, con la ventaja de poseer un costo aproximadamente 10 veces menor. Con esta suspensión de liposomas se logró establecer un protocolo optimizado de transfección de células de salmón CHSE-214, con vectores eucarióticos, no mostrando efecto citopático atribuible al formulado (datos no incluidos) y permitiendo la expresión del gen incorporado a ambos vectores. Este trabajo es uno de los primeros en establecer un protocolo de transfección in vitro entre DOTAP y la línea celular CHSE-214, sólo la publicación de Marshall y col en 1999 hace mención a transfección de líneas celulares de peces. Los antecedentes recopilados podrán ser de utilidad para futuras pruebas in vivo de vacunas de ADN entregadas en alimento para peces si se considera que el vector pcDNA 4.0 HisMax I TOPO (Invitrogen) es una herramienta tecnológica versátil y con alto grado de expresión, dado su promotor de CMV, en sistemas eucariontes.

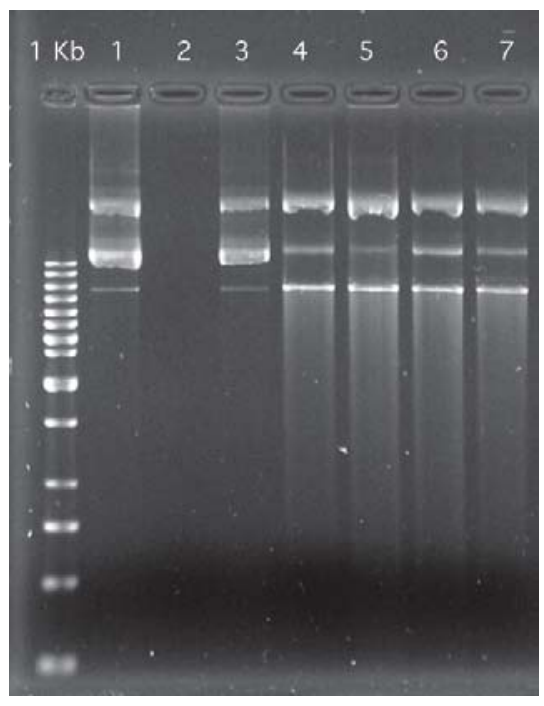

Figura 3. Protección del liposoma frente a la digestión de la enzima ADNsa I. El lipoplex con ADNp:DOTAP en una relación de 1:4 fue incubado a diferentes tiempos con ADNsa I para evaluar su nivel de protección. (1) ADNp desnudo; (2) ADNp incubado con ADNsa I; (3) lipoplex; (4), (5), (6) y (7) lipoplex incubado con ADNsa I durante 0, 10, 20 y 30 minutos respectivamente.

Protection against DNAse I digestion. The lipoplex with a DNAp:DOTAP ratio of 1:4 was incubated at different times with DNAse I to evaluate its level of protection. (1) Naked DNAp, (2) DNAp + DNAse I (3) Lipoplex, (4), (5), (6) y (7) Lipoplex + DNAse I at $0,10,20$ y 30 minutes.

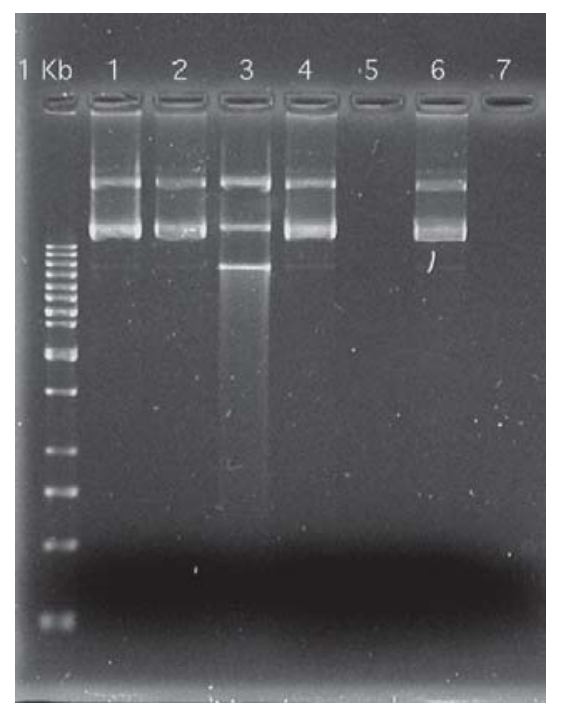

Figura 4. Interacción entre el plásmido y el liposoma. Para evaluar la interacción entre el ADNp y DOTAP y confirmar su estabilidad mediada por carga, el lipoplex fue expuesto a heparina y ADNsa I. (1) plásmido; (2) lipoplex; (3) lipoplex + ADNsa I; (4) lipoplex + heparina al 2\%; (5) lipoplex + heparina al 2\% + ADNsa I; (6) lipoplex + heparina al 5\%; (7) lipoplex + heparina al $5 \%$ + ADNsa I.

Plasmid-liposome interaction. To evaluate the DNAp: DOTAP interaction and to confirm its stability by charge, the lipoplex was exposed to heparin and DNAse I. (1) Plasmid (2) Lipoplex, (3) Lipoplex + DNAse I, (4) Lipoplex + Heparin 2\%, (5) Lipoplex + Heparin $2 \%$ + DNAse I, (6) Lipoplex + Heparin 5\%, (7) Lipoplex + Heparin 5\%+DNAse I.

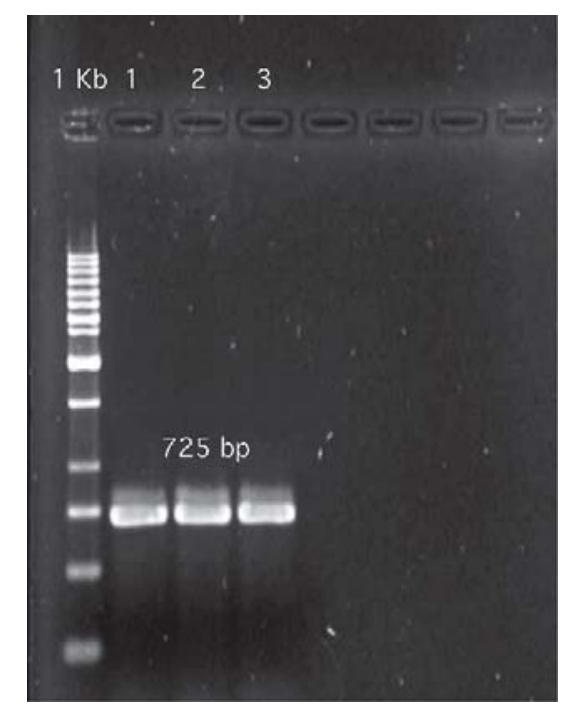

Figura 5. Expresión del gen reportero en las células transfectadas. A partir de lisado celular obtenido a 6,12 y $24 \mathrm{~h}$ posttransfección se obtuvieron amplicones por RT-PCR del ARNm producido desde el inserto clonado en el vector pcDNA 4.0 HisMax I TOPO.

Reporter gene expression in the transfected cells. Amplicons were obtained by RT-PCR of cellular lysate at 6,12 and $24 \mathrm{~h}$ posttransfection, which contained mRNA produced in vitro from insert cloned in the pcDNA 4.0 HisMax I TOPO vector. 


\section{RESUMEN}

El rápido crecimiento de la acuicultura chilena ha incentivado la exploración de estrategias innovadoras de prevención sanitaria. Las vacunas de ADN se presentan como una alternativa viable para el control de enfermedades, pero existen barreras técnicas, como la vía de administración y los sistemas de transporte y entrega que necesitan ser soslayados. Los liposomas catiónicos son utilizados ampliamente en la incorporación de genes en líneas celulares mamíferas pero su alto costo hace prohibitivo su uso en escala comercial. Con el fin de abordar la problemática económica en la obtención del liposoma y para contribuir con un procedimiento de transfección in vitro en células de salmón, los objetivos de este trabajo fueron formular un liposoma a partir de polvo liofilizado de DOTAP y desarrollar un protocolo de transfección de vectores eucarióticos en la línea celular CHSE-214. Para ello se utilizaron los vectores pcDNA 4.0 HisMax I TOPO y pIRES-EGFP y la línea celular de salmón Chinook CHSE-214 (ATCC 1681), estableciendo tanto las características del liposoma formulado como las condiciones óptimas de transfección. Los resultados indicaron que el liposoma formulado desde polvo liofilizado de DOTAP comparte todas las características de los liposomas comerciales con la ventaja de poseer bajo costo, aproximadamente 10 veces menos. Con este liposoma se logró establecer un protocolo óptimo de transfección de células de peces CHSE-214, con vectores eucarióticos, no mostrando signos de toxicidad y permitiendo la expresión del gen incorporado en ambos vectores.

\section{AGRADECIMIENTOS}

Este trabajo fue financiado a través de un proyecto INNOVA BioBio y por la Universidad de Concepción. Los autores desean agradecer a Ricardo Villegas, Patricio Oyarzún, Alejandro Capdeville y Luis Kriman por su asesoramiento durante el desarrollo del proyecto.

\section{REFERENCIAS}

Ahearn A, R Malone. 1999. Models of cationic liposome mediated transfection. Gene Ther Mol Biol 4, 159-170.

Felgner J, R Kumar, C Sridhar, C Wheeler, Y Tsai, R Border, P Ramsey, M Martin, P Felgner. 1994. Enhanced gene delivery and mechanism studies with a novel series of cationic lipid formulations. J Biol Chem 269 (4), 2550-2561.

Felgner P, T Gadek, M Holm, R Roman, H Chan, M Wenz, J Northrop. 1987. Lipofection: a highly efficient, lipid-mediated DNAtransfection procedure. P Natl Acad Sci USA 87, 7413-7417.

Jork H, W Funk, W Fisher, H Wimmer. 1990. Reagents and detection methods en: Thin-Layer Chromatography, Physical and Chemical Detection Methods: Fundamentals, Reagents I. Volume 1a, VCH Verlagsgesellschaft mbH, D-6940 Weinheim, Germany, Pp 464.
Marshall S, P Villalobos, V Rojas, P Conejeros. 1999. Lipopolyamine mediated transfection of reporter plasmid into a fish cell line. Electron J Biotechn 2, 88-98.

Moret I, J Peris, V Guillem, M Benet, F Revert, F Dasí, A Crespo, S Aliño, 2001. Stability of PEI-DNA and DOTAP-DNA complexes: effect of alkaline $\mathrm{pH}$, heparin and serum. $J$ Control Release 76, 169-181.

Perrie Y, P Frederik, G Gregoriadis. 2001. Liposome-mediated DNA vaccination: the effect of vesicle composition. Vaccine 19, 33013310.

Rädler J, I Koltover, T Salditt, C Safinya. 1997. Structure of DNAcationic liposome complexes: DNA intercalation in multilamellar membranes in distinct interhelical packing regimes. Science 275, 810-814.

Romoren K, B Thu, G Smistad, O Evensen. 2002. Immersion delivery of plasmid DNA. I. A study of potentials of a liposomal delivery system in rainbow trout (Oncorhynchus mykiss) fry. J Control Release 85, 203-213.

Romoren K, B Thu, N Bols, O Evensen. 2004 . Transfection efficiency and cytotoxicity of cationic liposomes in salmonid cell lines of hepatocyte and macrophage origin. Biochem Biophys Acta 1663 , 127-134.

Romoren K, B Thu, O Evensen. 2004․ Expression of luciferase in selected organs following delivery of naked and formulated DNA to rainbow trout (Oncorhynchus mykiss) by different routes of administration. Fish Shellfish Immun 16, 251-264.

Simberg D, D Danino, Y Talmon, A Minsky, M Ferrari, C Wheeler, Y Barenholz. 2001. Phase behaviour, DNA ordering, and size instability of cationic lipoplex. J Biol Chem 276 (50), 47453 47459.

Weber S, D Fichtner, T Mettenleiter, E Mundt. 2001. Expression of VP5 of infectious pancreatic necrosis virus strain VR299 is initiated at the second in-frame start codon. J Gen Virol 82 , 805-812.

Wiethoff C, M Gill, G Koe, J Koe, R Middaugh. 2002. The structural organization of cationic lipid-DNA complexes. J Biol Chem 277, 44980-44987.

Xu Y, F Szoka Jr. 1996. Mechanism of DNA release from cationic liposome/DNA complexes used in cell transfection. BiochemistryUSA 35, 5616-5623.

Xu Y, S Hui, P Frederik, F Szoka Jr. 1999. Physicochemical characterization and purification of cationic lipoplexes. Biophys $J 77$, 341-353.

Yu H, J Lin. 2000. Intracellular delivery of membrane impermeable hydrophilic molecules to a hepatoblastoma cell line by asialoglycoprotein-labeled liposomes. J Formos Med Assoc 99, 936-941.

Zabner J, A Fasbender, T Moninger, K Poellinger, M Welsh. 1995 Cellular and molecular barriers to gene transfers by cationic lipid. J Biol Chem 270, 18997-19007.

Zelphati O, F Szoka Jr. 1996. Mechanism of oligonucleotide release from cationic liposomes. P Natl Acad Sci USA 93, 11493-11498. 